\title{
LINCHAMENTO: A PUNIÇÃO COMO RESTITUIÇÃO DA ORDEM
}

\author{
LINCHAMIENTO: LA PUNICION COMO RESTITUCION DEL ORDEN
}

LYNCHING: THE PUNISHMENT AS A RESTITUTION OF THE ORDER

RESUMO: O presente ensaio propõe uma reflexão acerca da prática do linchamento enquanto comportamento coletivo presente na sociedade brasileira. Exploramos em nossa análise a dimensão simbólica do linchamento, ou seja, as motivações presentes na consciência coletiva da sociedade brasileira que corroboram para que tal ato aconteça. Admitimos, portanto, que a sociedade faz uso do linchamento amparada por uma ideia de cosmologia social que deve ser mantida e assegurada, garantindo que as suas referências de sociabilidade não sejam abaladas. Trouxemos como exemplo um caso de linchamento ocorrido no país, de modo a apreendermos, através dos vários discursos que se verificam sobre o ocorrido qual a percepção da comunidade, como a mesma se comporta diante deste tipo de situação; sendo os dados e informações sobre o caso retirados da imprensa.

PALAVRAS-CHAVE: Comportamento coletivo. Contingencial. Justiça com as próprias mãos. Sistema simbólico. Fronteiras simbólicas. Violência.

RESUMEN: El presente artículo propone una reflexión acerca de la práctica del linchamiento como comportamiento colectivo presente en la sociedad brasileña. Exploramos en nuestro análisis la dimensión simbólica del linchamiento, o sea, las motivaciones presentes en la conciencia colectiva de la sociedad brasileña que corroboran para que tal acto suceda, admitimos por lo que la sociedad hace uso del linchamiento amparado por una idea de cosmología social que debe ser mantenida y asegurada, garantizando que sus referencias de sociabilidad no sean sacudidas. Hemos traído como ejemplo un caso de linchamiento ocurrido en el país, de modo que aprehendemos a través de los diversos discursos que se verifican sufre lo ocurrido cual la percepción de la comunidad, como la misma se comporta ante este tipo de situación; siendo los datos e informaciones sobre el caso retirados de la prensa.

PALABRAS CLAVE: Comportamiento colectivo. Contingencia. Justicia con sus propias manos. Sistema simbólico. Fronteras simbólicas. Violencia.

ABSTRACT: The current article proposes a reflection around the lynch practice while a collective behavior that occurs in the Brazilian society and also invites us to explore in our own analysis the symbolical dimension of the lynching, in other words, the current motivations in the collective conscious of the Brazilian society that contributes with the existence of such act. Therefore, we admit that the society uses the lynching practice protected by the idea of a social cosmology that must be sustained and ensured, what guarantee that your sociability references

${ }^{1}$ Universidade Estadual Paulista (UNESP), Araraquara - SP - Brasil. Graduando em Ciências Sociais. ORCID: <https://orcid.org/0000-0003-4181-7861>.E-mail: flavio_eduardo12@hotmail.com 
doesn't get damaged. We brought as an example a lynching case occurred in Brazil, in order to learn throughout the amounts of speeches that emerge about the case, what is the community perception and how the same behaves before this kind of situation. The data and the information's about the case are taken of the press.

KEYWORDS: Collective behavior. Contingency. Justice with his own hands. Symbolic system. Symbolic boundaries. Violence.

\section{Introdução}

O presente ensaio discute acerca das questões relativas ao linchamento, popularizado por "justiça com as próprias mãos", partindo de um caso em específico, ocorrido na zona sul do Rio de Janeiro. Buscamos compreender as relações sociais que são mobilizadas, ou seja, os agentes enquanto produtores de poder, que através do uso da força delimitam o espaço social ao qual estabelecem o seu pertencimento. Assumimos uma postura epistemológica que apreende o linchamento enquanto um comportamento coletivo. Dessa forma buscamos construir uma interpretação possível, dentre outras tantas, sobre esse fenômeno. Pressupomos que a interpretação aqui esboçada se realiza a partir de outras interpretações, ou seja, através das narrativas da imprensa e dos indivíduos presentes no linchamento. Esta perspectiva epistemológica se apresenta na proposta de Clifford Geertz (1926), na qual o autor propõe inscrever a realidade do seu objeto de pesquisa através das narrativas presentes pelos seus informantes, assim como daquelas pessoas constituintes do seu espaço de pesquisa, a investigação do seu objeto só é possível portanto, pelas várias narrativas presentes.

Se a interpretação antropológica está construindo uma leitura do que acontece, então divorciá-la do que acontece - do que, nessa ocasião ou naquele lugar, pessoas específicas dizem, o que elas fazem, o que é feito a elas, a partir de todo o vasto negócio do mundo - é divorciá-la das suas aplicações e torná-la vazia (GEERTZ,1926, p. 13).

Ao assumir tal postura, o presente ensaio não busca exaurir o tema, mas instigar os estudos sobre o mesmo, em uma clara perspectiva que considera a pesquisa sociológica enquanto um exercício de contínua construção, desde a investigação do nosso objeto, o qual consiste na retirada de notícias divulgadas pela imprensa, desenvolvendo posteriormente as respectivas reflexões produtoras de sistematizações conceituais. É preciso salientar, como ressalta José de Souza Martins, que o estudo do justiçamento se faz em construção, primeiro pelo pouco interesse demonstrado pelos sociólogos brasileiros em estudar o tema, segundo pela 
própria natureza do tema, que se dá de maneira contingencial e ocasional, sendo o material disponível para investigação basicamente o proveniente da imprensa.

\section{Conceituação do tema}

A violência no meio urbano se faz presente na sociedade brasileira, seja ela motivada pelas facções criminosas, pelos altos índices de marginalidade, ou por veículos institucionais, como o uso truculento da força pela polícia militar. O advento da urbanização, intensificado a partir da década de 30, trouxe uma nova dinâmica social ao país: não eram mais os valores tradicionais do mundo rural que regiam e intermediavam as relações dos indivíduos (garantindo uma sociabilidade específica voltada na pessoalidade e na troca de favores), mas os valores derivados de uma organização social estabelecida por instituições reguladoras da vida individual e coletiva, principalmente pelo uso da força legítima institucional, expressa pela polícia.

A violência, neste sentido, não seria contida pela motivação pessoal como acontecia no Brasil rural, marcada pela presença dos capangas (de forte caráter pessoalista, eram indivíduos assalariados responsáveis pela defesa do patrão) que dentro das noções de justiça, assentados no imperativo rural, cumpriam funções repressivas. A organização da vida pública no ambiente urbano rompe com essa dinâmica na medida em que as relações de pessoalidade se distanciam, não é mais o coronel grande proprietário de terras que dita as regras repressivas, mas sim o Estado, através do aparato jurídico e em especial da polícia civil, garantidora da ordem pública.

Este contexto sócio-histórico de formação da urbanização brasileira nos auxiliará a entender atos de violência que se fazem presentes na sociedade, e que só podem ser estudados em sua complexidade se estiverem historicamente definidos e simbolicamente apreendidos, a fim de se estudar os motivadores de atos violentos, em específico os chamados linchamentos, ou como se popularizou "justiça com as próprias mãos".

Caracterizado por um ato de violência coletiva, o linchamento ocorre de maneira contingencial, no qual cidadãos comuns praticam atos violentos como o apedrejamento ou a mutilação corporal.

A ação destina a violar o corpo do indivíduo, que cometendo um crime ou infringindo uma norma padrão vigente na comunidade em que está inserido, deve ser imediatamente repreendido. De fato, é necessário distinguir o ato de linchar em relação a outras modalidades de violência, como, por exemplo, a chacina, a qual consiste na ação de matar muitas pessoas ao 
mesmo tempo de modo intenso, ou seja, um assassinato cruel e brutal, cujo massacre provoca comoção, revolta e temor por parte da sociedade, sendo a do Carandiru (1992) e da Candelária (1993) os casos mais expoentes no Brasil. De maneira oposta, no linchamento não se observa a morte de várias pessoas, restringindo-se muitas vezes a um indivíduo, prática que ocorre na maioria das vezes com a utilização de armas brancas, pedras ou o próprio espancamento, dada a natureza do fenômeno: caracterizado não por uma ação que prescinde uma organização definida (o que sociologicamente pode se considerar como um movimento). Dada a constatação de que o crime foi cometido, os cidadãos executam o ato de linchar com os utensílios que lhes estão mais próximos, raramente se observa a utilização de arma de fogo, por exemplo, uma vez que se trata de cidadãos comuns, muitas vezes residentes locais, comerciantes de uma dada localidade.

Pode-se salientar que, de maneira peculiar, o linchamento decorre da motivação para a prática parte da insatisfação de um grupo comunitário que compartilha de um mesmo sistema valorativo, nos termos durkheimiano de uma consciência coletiva comum (DURKHEIM, 1895). A infração de um membro dessa coletividade para com os imperativos normativos da conduta social abala o sistema valorativo comum, assim como o sistema simbólico. Sendo assim, a principal estrutura que norteará a nossa indagação sobre o estudo da natureza, assim como das características específicas desse fenômeno, o linchamento, será apreendê-lo enquanto um ato coletivo que possui motivações simbólicas para que ocorra, na medida em que os indivíduos presentes nestes atos comungam de um mesmo sistema simbólico do que se considera como justo e injusto, certo ou errado. A construção desse pensamento dicotômico pressupõe que qualquer desvio da normalidade coloca em risco a permanência desse sistema de pertencimento coletivo.

\section{Contribuições teóricas para o entendimento do fenômeno}

A partir dessa problemática observam-se as contribuições presentes na obra do sociólogo José de Souza Martins (2015), expoente na pesquisa do tema. Na sua obra Linchamentos: a justiça popular no Brasil o mesmo executa uma investigação sobre a natureza dessa modalidade de violência, que, para ele, advém do Brasil pré-colonial até os dias de hoje. Ao explicar a forma e a função da justiça popular no Brasil, o autor encontra evidências da força do inconsciente coletivo e do que ele chama de "estruturas sociais profundas", que permanecem latentes nas referências atuais de condutas sociais e em comportamentos 
individuais. Essas estruturas sociais, segundo ele, não foram superadas pela história e permanecem como referências profundas das ações sociais de hoje. A interessante contribuição do autor para a nossa reflexão consiste, por exemplo, quando o mesmo explicita que a concepção dos linchamentos e os rituais são expressão da força da tradição presentes da sociabilidade do mundo rural.

[...] ganha sentido nos costumes funerários da sociedade brasileira, ainda fortes nas regiões rurais. São verdadeiras sobrevivências de arqueologia simbólica e imaterial que um dia dominaram, no Brasil, nossas concepções sobre a vida e a morte e o modo como se determinam reciprocamente (MARTINS, 2015, p.10).

Dentro dessa análise ritual do linchamento, observa-se outro fator presente como um motivador para que a prática ocorra, o distanciamento com a ordem legal vigente e a não identificação com as instituições responsáveis pelo uso da força legítima, como a polícia e a legislação normativa, sinalizando para o cidadão que a reparação do crime só ocorre de maneira efetiva quando o infrator sofre a agressão física, assim como a exposição pública. Expoente em situações de desagregação social em relação aos veículos institucionais, o linchamento, segundo aponta Martins, sinaliza para um fenômeno de violência criador da sociabilidade enquanto espaço de constrangimentos.

O linchamento enquanto um rito sacrificial se formula a partir de um processo de identificação, do grupo que comunga do mesmo sistema simbólico. Esse nos relaciona em relação à sociedade de forma ampliada, ou seja, daquele grupo comunitário em relação à sociedade brasileira, em um processo que leve a acusar o indivíduo que cometeu o crime. A eficácia do ato funciona, portanto, como controle social pela intimidação e envergonhamento do linchado. Esse processo de desculpa pública e a acusação do infrator estabelecem a manutenção do sistema, na medida em que irá reafirmar os valores locais, executando um processo que reafirma o sentimento de pertença dos que praticam juntos o ato de linchar, essa comunhão valorativa.

Portanto, Martins traz a análise de que nos linchamentos se observa um esforço social para que se repare de alguma maneira a ordem moral e cósmica. A lógica dessa ação coletiva funciona com o mecanismo de reparar as categorias simbólicas que estão profundamente enraizadas na mentalidade coletiva, os quais persistem mesmo após uma mudança valorativa presente na dinâmica rural, que se perpetua dentro da configuração propriamente urbana, coexistindo com os modernos valores individuais $\mathrm{e}$ instrumentais presentes na contemporaneidade. 
Os linchamentos constituem resposta ao que é a transgressão do limite do socialmente tolerável. Mesmo numa sociedade em que as identidades são de indivíduos, sujeitos de relações societárias (e não predominantemente de pessoas, sujeitos de relações comunitárias) e de relações em princípio predominantemente contratuais, a partir desse limite os mecanismos de sociabilidade próprios dessa sociedade aparentemente deixam de funcionar. E são imediatamente supridos por outros mecanismos de interpretação e ação, mantidos em latência, ativados quando o código dominante é bloqueado por não conter no elenco de seus procedimentos, interpretações e recomendações as informações apropriadas para revestir de sentido e de aceitação atos de violação da condição humana e da sociabilidade mínima que lhe corresponde (MARTINS, 2015, p. 66).

Martins, ao desenvolver essa análise que aponta a permanência das categorias simbólicas no inconsciente coletivo, possibilita que tratemos a temática com especial atenção. Sendo assim, é possível observar que a manutenção desta cosmologia se reverbera com tamanha atrocidade na violência física.

\section{Linchamento enquanto uma categoria simbólica da violência}

A prática social de classificar a fim de se obter a diferenciação social, analisada por Bourdieu, permite considerar como os indivíduos formulam as suas identidades, mas também a maneira pela qual irão articular as suas relações. Ao praticar o linchamento, o grupo social responsável pela ação é motivado pelo descontentamento em relação a uma prática executada pelo linchado, tida como transgressora no que se refere à ordem moral estabelecida naquela comunidade. A repulsa geradora do ato pode ser até mesmo contra a um pertencimento social que não o da comunidade, como no caso que analisaremos mais adiante, trazendo a dimensão estratificante presente na sociedade brasileira, ou seja, cada grupo social possui o seu espaço urbano previamente estabelecido segundo a sua classe socioeconômica.

Esta consideração inicial parte de um caso pelo qual iremos abordar, de um adolescente negro da periferia do Rio de Janeiro que começa a ser perseguido e posteriormente linchado pelos moradores de um bairro de classe média alta, acusado de praticar furtos na região. Utilizase do constrangimento social e da violência como finalidade coercitiva, assim como é dispensada pelos moradores qualquer mobilização que venha do Estado, como a polícia. De fato, não se buscou comprovar se o jovem executava os atos de furto, mas pela sua origem racial e social, pressupunha-se que o mesmo era culpado e que não deveria estar naquele espaço urbano.

O debate que tentaremos estabelecer com o autor é em relação ao uso do poder simbólico que historicamente está nas mãos do Estado, sendo este último concebido como um 
conjunto de agentes e instituições, que exerce a autoridade soberana sobre um grupo de indivíduos especificamente localizados, expressando de forma legítima esse grupo. Sendo assim, o Estado sublinha esta "instância oficial, reconhecida como legítima, isto é, como detentora do monopólio da violência simbólica legítima" (BOURDIEU, 1984, p. 490).

Bourdieu (1984) afirma que o habitus possui influência no comportamento humano, constituindo as nossas relações por normas de conduta e formas de ser que não estão explicitamente racionalizadas, ou seja, naquilo que não nos damos conta. A constituição dos diferentes habitus traz consigo a formação dos grupos sociais que, através do poder simbólico, demarcam as fronteiras sociais, constituindo um modo de coerção para com uma conduta que não é vista como legítima, que não corresponde à sua.

\begin{abstract}
As diferentes classes e fracções de classes estão envolvidas numa luta propriamente simbólica para imporem a definição do mundo social mais conforme aos seus interesses, e imporem o campo das tomadas de posições ideológicas reproduzindo em forma transfigurada o campo das posições sociais. Elas podem conduzir esta luta quer diretamente, nos conflitos simbólicos(produtores a tempo inteiro) e na qual está em jogo o monopólio da violência simbólica legítima (cf.Weber), quer dizer, do poder de impor - e mesmo inculcar - instrumentos de conhecimento e de expressão (taxinomiais) arbitrários - embora ignorados como tais - da realidade social. O campo de produção simbólica é um microcosmos da luta simbólica entre as classes: é ao servirem os seus interesses na luta interna do campo de produção (e só nesta medida) que os produtores servem os interesses dos grupos exteriores ao campo de produção (BOURDIEU, 1989 p. 12-13).
\end{abstract}

Acerca dessa conceituação presente no pensamento do autor sobre o Estado, partimos para a perspectiva durkheimiana presente em Bourdieu, em que se pode verificar a análise que considera o Estado como fundamento da integração moral, através da difusão de valores a lógica do compartilhamento das mesmas categorias de percepção do mundo social, isto se reverbera em princípios para se obter a construção de consensos. O potencial do Estado é questionado quando se verifica um descrédito em sua capacidade em manter a ordem social e cosmológica estabelecida, a qual, no caso do justiçamento, acaba sendo restabelecida pelos próprios cidadãos. Nosso empreendimento aqui não é invalidar o argumento de Bourdieu, mas tentar mostrar como o linchamento pode sinalizar um fenômeno de violência peculiar dentro da tradicional concepção de violência simbólica. Essa dimensão do simbólico acaba sendo exercida não mais pelo Estado, que forja sua autoridade sobre a égide do poder simbólico, mas pelos indivíduos da comunidade, que buscam restituir a cosmologia local.

[...] A construção do Estado como campo relativamente autônomo exercendo um poder de centralização da força física e da força simbólica, e constituindo assim um embate de lutas, é inseparavelmente acompanhado pela construção 
de um espaço social unificado que lhe serve de base (BOURDIEU, 1989 p. 197).

Sendo assim, o Estado - enquanto este campo de lutas - perde força na medida em que esses confrontos não se dão a partir das instâncias institucionais, como a repressão policial, ou o julgamento jurídico. A capacidade de administrar as tensões sociais é colocada em questão, o direito de julgar e ser julgado não encontra mais um obstáculo, o Estado, este que antes sinalizava o aglutinador da vida social, nas palavras do autor "a última instância à qual se pode recorrer" (BOURDIEU, 1989, p. 114, 324 e 328). Todavia, em última instância, observa-se a permanência de uma função social que se manifesta de maneira evidente no caso dos linchamentos: a exposição pública enquanto performance que só encontra eficácia simbólica efetiva uma vez que o ato é praticado publicamente. Porém, tal manifestação não parte mais uma vez da centralidade do Estado, mas sim dos próprios indivíduos.

Essas comissões públicas são encenações, operações consistindo a desempenhar algo como um drama público, o drama da reflexão sobre os problemas públicos [...] O problema público é um problema que merece ser tratado publicamente, oficialmente (BOURDIEU, 1989, p. 30 e 47).

O Estado não é destituído do poder simbólico, não é disso que se trata, mas observa-se a força social, que mobilizada pelo descrédito nas instituições oficiais, atribui para si o papel de agente que estabelece a ordem social e cosmológica convencionada. Evidencia-se como o poder simbólico, aquele que permeia a construção das convenções sociais, é exercido pelo cidadão, de maneira a constranger a realidade diversa a sua.

\section{Episódio de linchamento ocorrido no país}

O caso se passa na Zona Sul do Rio de Janeiro, bairro do Flamengo, no ano de 2014. Um adolescente negro de 15 anos foi espancado, esfaqueado na orelha e preso a um poste por uma trava de bicicleta. Segundo relatos de alguns moradores, o adolescente foi atacado por três homens nomeados de "os justiceiros". O ato foi filmado por vizinhos e postado nas redes sociais. O linchado só foi socorrido após alguns moradores, entre eles Yvonne Bezerra de Melo, terem sido informados sobre o ocorrido. Yvonne acionou o corpo de bombeiros que socorreu o jovem.

O linchamento do Rio, além de evidenciar um nítido caso de racismo, nos permite observar algumas proposições trabalhadas acerca da natureza do fenômeno: os indivíduos comungam de um mesmo sistema valorativo que legitima o ato de violência, ao se posicionar 
de maneira favorável ao que foi promovido pelos justiceiros, os cidadãos ao redor, mesmo não tendo participando do ato corroboram para que o mesmo seja legitimado.

Eu não quero saber se ele é bandidinho ou bandidão, você não pode amarrar uma pessoa no meio da rua. Aquela área do Flamengo teve um aumento muito grande de violência e roubos recentemente. Como as coisas não melhoram, um bando de garotões se juntam e começam a fazer justiça pelas próprias mãos. Sei que tem muita marginalidade e a polícia é ineficaz, mas você não pode juntar um grupo e começar a executar pessoas [...] Eu perguntei a ele quem tinha feito aquilo e ele disse que eram os "justiceiros de moto". Ele foi espancado, levou uma facada na orelha, arrancaram a roupa dele e prenderam pelo pescoço. E ninguém na rua faz nada para impedir (YVONNE, 2014).

O relato de Yvonne, quando entrevistada, possibilita observarmos a descrença no papel do Estado, simbolizado pela polícia como garantidor da ordem, o que se busca em atos como o dos "justiceiros de moto" é intimidar outros indivíduos que possam vir a cometer assaltos ou simplesmente transitar pela região: "pra servir de exemplo aos pretos ladrões".

A presença das redes sociais como potencializador da divulgação do ato chocam pela não intimidação dos moradores em se posicionar de maneira favorável ao linchamento, demonstrando apoio aos "justiceiros". As redes sociais enquanto espaço da sociabilidade na era da informática assiste a manifestação dos discursos de ódio e poder produzidos pelos grupos sociais. O preconceito racial se faz evidente quando se admite tal prática como aceitável devido ao indivíduo a que se destina: "Esse tipo de crime tem muito racismo, muito preconceito. Se fosse o contrário, ia ser um Deus nos acuda. O branquinho amarrado no poste, coitadinho!" (YVONNE, 2014, s/p).

\section{Considerações finais}

O fenômeno do linchamento consiste em um ato de violência contingencial, sendo os casos mais recorrentes os presentes nas regiões urbanas do país, em que a credibilidade das instituições oficiais do uso da força legítima é vista como ineficaz a uma efetiva restituição da ordem, tal como pudemos notar em Martins. A cosmologia valorativa própria do grupo que executa o linchamento representa o motim para que a prática se efetive portanto, a restituição da ordem só ocorre com o justiçamento.

Compreender o fenômeno não somente como uma ação de violência coletiva, mas a partir de sua dimensão simbólica nos auxilia a compreender as motivações que se fazem presente e que se efetivam nos campos sociais tal como Bourdieu concebe linchar o indivíduo 
que executa uma ação não condizente com a prescrição do seu grupo é manter a cosmologia local.

Compreender o fenômeno é debruçar-se sobre os dados que nos auxiliam a compreender a sua natureza. As fontes provenientes da imprensa, mesmo possuindo as suas ressalvas contribuem, pois, através desta fonte. Podemos analisar o discurso de cada indivíduo (dona Yvonne que é contra o ato, e depoimentos dos moradores favoráveis) a fim de mostrar a dimensão social do linchamento. Ao apontar os sujeitos em questão, apontam para as potenciais motivações que os mesmos comungam e que os levam a praticar tal ato, o qual consiste em balizar os espaços sociais de cada sujeito.

Este trabalho propõe, portanto, através do diálogo com autores que discutem a questão da violência, seja ela no plano simbólico, seja quando materializada na violação do corpo alheio, conduzir a um estudo que compreenda o fenômeno enquanto fruto das produções humanas de sociabilidade no meio urbano.

\section{REFERÊNCIAS}

BOURDIEU, Pierre. Homo academicus. Paris: Minuit, 1984.

BOURDIEU, Pierre. O poder simbólico. Lisboa: Difel, 1989.

ESTADÃO. Adolescente é amarrado e quase linchado após assalto na zona sul do Rio. Portal UOL, Rio de janeiro, 26 jun. 2014. Disponível em: https://noticias.uol.com.br/cotidiano/ultimas-noticias/2014/02/26/adolescente-e-amarrado-equase-linchado-apos-assalto-na-zona-sul-do-rio.htm. Acesso em: 16 nov. de 2018.

GEERTZ, Clifford. A interpretação das culturas. 1. ed. Rio de Janeiro: LTC, 2008.

MARTINS. José de Souza. Linchamentos: a Justiça Popular no Brasil. São Paulo: Contexto, 2015.

PORTAL G1. Adolescente é espancado e preso nu a poste no Flamengo, no Rio. G1 Globo, Rio de Janeiro, 03 fev. 2014. Disponível em: http://g1.globo.com/rio-dejaneiro/noticia/2014/02/adolescente-e-espancado-e-preso-nu-poste-no-flamengo-no-rio.html. Acesso em: 13 nov. de 2018.

\section{Como referenciar este artigo}

ANDRADE, Flávio Eduardo de. Linchamento: a punição como restituição da ordem. Rev. Sem Aspas, Araraquara, v. 7, n. 2, p. 292-301, jul./dez., 2018. E-ISSN: 2358-4238. DOI: 10.29373/sas.v7i2.12497 